\title{
Anal intercourse and idiopathic infertility: Anatomical considerations and authors' perspective
}

\author{
Abdelmonem Awad Hegazy ${ }^{1 *}$ and Mustafa Abdelmonem Hegazy ${ }^{2}$ \\ ${ }^{1}$ Professor and Former Chairman of Anatomy and Embryology Department, Consultant of Obstetrics and Gynecology, Faculty of Medicine, Zagazig University, \\ Egypt \\ ${ }^{2}$ Physician, Zagazig University Hospitals, Faculty of Medicine, Zagazig 44519, Egypt
}

\begin{abstract}
Identification of causes of infertility could improve the chances for the management. The unexplained or idiopathic causes represent up to $30 \%$ for the infertility cases. One of such causes might be the unprotected anal intercourse due to the high possibility of lacerations and injuries occurring through the thin mucosa of anal canal. Escape of sperms into the injured female tissues might encourage her body to develop antibodies against the seminal content of male partner and causing infertility. Future studies are recommended to clarify such possibility as well as to develop a new contraceptive method depending on the immunity.
\end{abstract}

\section{Introduction}

Idiopathic infertility is the failure of spontaneous pregnancy despite the presence of regular unprotected vaginal intercourse without presence of obvious cause. The parameters of the routine infertility investigations are within the reference values. Such parameters include the semen analysis, ovulation tests, hysterosalpingography and if indicated laparoscopic examination and ovarian reserve [1]. Unexplained infertility accounts for about $15-30 \%$ of cases of infertile couples [2]. Clarifying new causes of infertility will diminish the prevalence unexplained cases; and this could assist in their good management. Idiopathic infertility might be caused by many factors such as hysterosalpingography we previously suggested [3]. Another cause could result from lacerations and injuries produced in females at sexual intercourse either vaginal or anal. The last route is the more prone to laceration due to its different anatomical features. Therefore, this short review article aimed to highlight the possible role of anal intercourse in subsequent female infertility, taking the anatomical features into consideration.

\section{Anal canal}

Anal canal is about four cm in length; and usually shorter in females than males. It is composed of two developmentally portions; inner endodermal and outer ectodermal portions. Therefore, its lining differs in its various parts. Except the distal "ectodermal" part, the upper half of anal canal is lined with simple "one layered" columnar epithelium with highly vascular subepithelial tissue [4]. While, the lower part is lined with modified skin (thin, smooth, non-keratiniazed stratified squamous lining; without hair or glands) till the terminal $0.5 \mathrm{~cm}$ that is lined with true skin (keratinized stratified squamous epithelium; with sweat and sebaceous glands). The line of junction of modified and true skin is called "white line". The mucous membrane of upper part of anal canal shows longitudinal folds "called anal (Morgagni) columns" (about 10 in number). These columns contain terminals of inferior mesenteric vessels. The lower ends of the columns are connected with crescent folds of mucosa, called anal valves. Each fold bounds a depression above it called anal sinus. The sinuses contain openings of anal glands (Figure 1). This line "anal valves" is called "dentate or pectinate" line [5]. It is a sawtoothed junction between the endoderm and ectoderm, representing the site of attachment of the cloacal membrane in intrauterine life. Pectinate line marks the zone of transition of mucosal lining from simple columnar to stratified squamous epithelium [6]. In addition, this part is insensitive to tear pain being supplied by autonomic nervous system [5]. This part could be subjected to injury or microabrasions due to frictions. Rupture of one of anal valve leads to fissure in ano; and associated with severe pain as it extends down to skin. The anal valves are covered by mucous membrane along its upper surface and skin on the lower surfaces [7]. Through these potential abrasions or wounds, sperm cells might enter the female body tissues at anal intercourse. In these cases, no obvious cause is evident; however, when one of the couples becomes divorced and marries another partner, pregnancy might occur.

Moreover, the anal canal isn't supported on either side except by the anal sphincters; external and internal. Instead, it is surrounded by a week loose areolar fatty area on each side called ischiorectal fossa. Such area represents a potential site for infections (Figure 1).

\section{Vagina}

The vagina versus the anal canal could withstand friction and distension. The mucosa of vagina shows folds that allow a great distension especially noticed at vaginal delivery. Vagina is lined with

${ }^{\star}$ Correspondence to: Abdelmonem Awad Hegazy, Professor and Former Chairman of Anatomy and Embryology Department, Consultant of Obstetrics and Gynecology, Faculty of Medicine, Zagazig University, Egypt, E-mail: dr.abdelmonemhegazy@yahoo.com

Key words: anal intercourse, infertility, immunological reactions, antisperm antibodies, conception

Received: December 07, 2018; Accepted: December 31, 2018; Published: January 03, 2019 


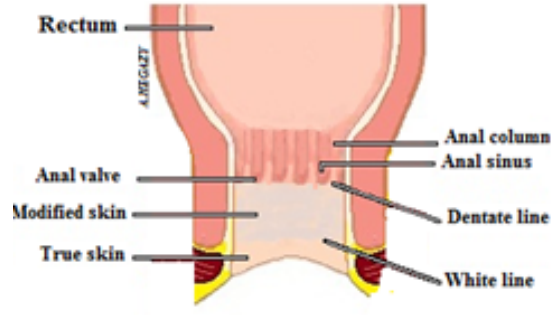

A

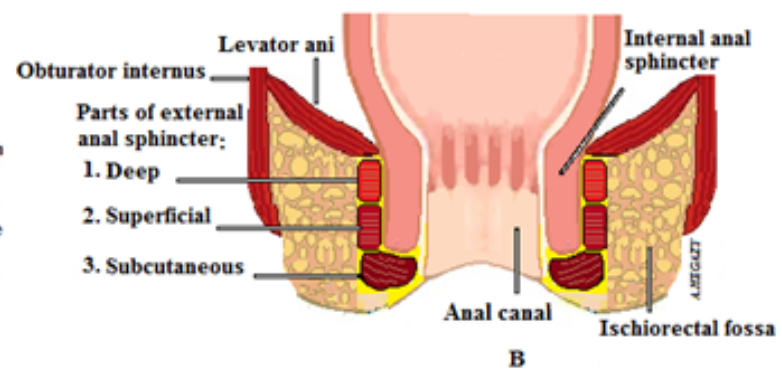

B

Figure 1. Anal canal anatomy (A) Internal features (B) Sphincters

stratified squamous epithelium. Under the effect of estrogen, the epithelial cells manufacture glycogen. The vaginal mucosa undergoes keratinization forming keratin plates like that found in the epidermis. With desquamation of these cells, the bacteria in vagina metabolize their glycogen into lactic acid. This lowers the vaginal $\mathrm{pH}$ and therefore protecting the vaginal wall against the pathogens and microorganisms. Moreover, the vaginal wall has a dense connective tissue rich in elastic fibers making it a strong and elastic structure [8]. This vaginal structure protects it against tear and wear that might occur due intercourse. Also, the acidity of vagina protects it from invasion of microorganisms and sperms. Moreover, the uterine cervix is a competent immune site. It contains immunoglobulin ( Ig A) located in the plasma cells of the subepithelial tissue of endocervix. This blocks the progress of potential invaders including the sperms from reaching up to the female genital tract through cross-linking them to the cervical mucus [9]. Sperm antibody activity has been detected in the cervical mucosa of more than $10 \%$ of total cases of unexplained infertility [10]. Therefore, there is no development of antisperm antibodies in females with repeated intravaginal insemination [11].

\section{Immunological reactions}

Invasion of spermatozoa through the lacerated tissue of female anal canal might cause formation of specific antibodies preventing fertilization. Development of female immunological reactions to sperms of her male partner could be involved in establishment of idiopathic infertility [12]. The development of female antibodies to sperms could also inhibit the in-vitro fertilization (IVF) $[13,14]$. Therefore, formation of sperm antibodies could impair the functions of sperms through impeding their ability to penetrate the cervical mucus or to achieve fertilization [12].

Early study during 1930s reported a trial for inducing immunecontraception by immunization of 20 fertile females through intramuscular injection of seminal fluid of their partners mixed with an antibacterial agent weekly for three weeks. Development of spermimmobilizing activity in the female serum was noticed; and remained for 6-12 months. One female became pregnant after about one year when the immunological reaction was no detected in her serum [15]. Franklin and Dukes found the presence of the sperm antibodies in women with unexplained infertility; and the titer was higher in these women $(72.1 \%)$ than in those with organic causes for infertility $(8.4 \%)$ [16]. Subsequent studies confirmed the role of sperm antibodies in inducing infertility $[17,18]$.

\section{Conclusions}

It is concluded that the anal canal of intercourse isn't equipped for sexual intercourse. This route is suggested to be avoided due to the possibility of development of immunological reactions to sperms and hence infertility later on. Future studies are recommended to clarify all aspects of sperm immunity in females that might occur following unprotected anal intercourse. Moreover, this might stimulate the research towards the development of antisperm vaccine as a contraceptive method inducing reversible but reliable sterility for human couples.

\section{Declarations}

Conflict of interest: None.

\section{Acknowledgements}

No funding was provided. The diagrams are done by the first authors.

\section{References}

1. Schattman GL, Esteves SC, Agarwal A (2015) Unexplained infertility: Pathophysiology, evaluation and treatment. Springer, New York, Heidelberg Dordrecht, London.

2. The practice committee of the american society for reproductive medicine (2016) Effectiveness and treatment for unexplained infertility. Fertil Steril 86: S111-S114. [Crossref]

3. Hegazy AA (2018) Hysterosalpingography might disturb the functional anatomy of Fallopian tube. Acad Anat Int 4: 1-3.

4. Pandey P (2012) Anal anatomy and normal histology. Sex Health 9: 513-516. [Crossref]

5. Sinnatamby CS (2006) Last's Anatomy: Regional and Applied. 11 th $e d$, Churchill Livingstone, Elsevier.

6. Hegazy A (2014) Clinical embryology for medical students and postgraduate doctors. Lambert Academic Publishing LAP, Berlin.

7. Du Plessis DJ (1975) A synopsis of surgical anatomy. $11^{\text {th }}$ ed, Bristol John Wright \& Sons ltd.

8. Mescher A (2016) Junqueira's basic histology text and atlas. 14th ed, McGraw-Hill Education - Europe.

9. Ingerslev HJ, Moller NP, Jager S, Kremer J (1982) Immunoglobulin class of sperm antibodies in cervical mucus from infertile women. Am J Reprod Immunol 2: 296-300.

10. Menge AC, Medley NE, Mangione CM, Dietrich JW (1982) The incidence and influence of antisperm antibodies in infertile human couples on sperm-cervical mucus interactions and subsequent fertility. Fertil Steril 38: 439-446. [Crossref]

11. Chamley LW, Clarke GN (2007) Antisperm antibodies and conception. Semin Immunopathol 29: 169-184. [Crossref]

12. Clarke GN (2009) Etiology of sperm immunity in women. Fertil Steril 91: 639-643. [Crossref]

13. Clarke GN, Lopata A, Johnston WI (1986) Effect of sperm antibodies in females on human in vitro fertilization. Fertil Steril 46: 435-441. [Crossref]

14. Clarke GN (1988) Sperm antibodies and human fertilization. Am J Reprod Immunol Microbiol 17: 65-71. [Crossref]

15. Baskin MJ (1932) Temporary sterilization by the injection of human spermatozoa. $\mathrm{Am}$ J Obstet Gynecol 24: 892-897.

16. Franklin RR, Dukes CD (1964) Antispermatozoal antibody and unexplained infertility. Am J Obstet Gynecol 89: 6-9. [Crossref] 
Hegazy AA (2019) Anal intercourse and idiopathic infertility: Anatomical considerations and authors' perspective

17. Yeh WR, Acosta AA, Seltman HJ, Doncel G (1995) Impact of immunoglobulin isotype and sperm surface location of antisperm antibodies on fertilization in vitro in the human. Fertil Steril 63: 1287-1292. [Crossref]
18. Ford WC, Williams KM, McLaughlin EA, Harrison S, Ray B, et al. (1996) The indirect immunobead test for seminal antisperm antibodies and fertilization rates at in-vitro fertilization. Hum Reprod 11: 1418-1422. [Crossref]

Copyright: (C2019 Hegazy AA. This is an open-access article distributed under the terms of the Creative Commons Attribution License, which permits unrestricted use, distribution, and reproduction in any medium, provided the original author and source are credited. 